\title{
Comparison of patterns of spatial variation of microgastropods between two contrasting intertidal habitats
}

\author{
C. Olabarria*, M. G. Chapman \\ Centre for Research on Ecological Impacts of Coastal Cities, Marine Ecology Laboratories A11, University of Sydney, \\ New South Wales 2006, Australia
}

\begin{abstract}
Small-scale spatial variation in the distribution of the macrofauna of marine intertidal shores has long been recognized, but there have been few quantitative studies about the scales of patchy distribution of the microbenthos on rocky shores. Patchiness has important implications for comparative and descriptive studies of distribution and abundance because it confounds comparisons of abundance at the largest spatial scales unless the smaller scales are appropriately incorporated into the sampling designs. Spatial variation in the distribution of a number of species of intertidal microgastropods across 2 different habitats (sediment and coralline turf) in Botany Bay, Australia, is described using a nested, hierarchical sampling design. Significant variation was detected mainly at small scales, ranging from less than 1 to $10 \mathrm{~m}$. Moreover, the species showed different patterns of variation depending on the type of habitat and the time of sampling. There was no relation between these patterns and the taxonomic relations of the species. These data illustrate the scales of variability that must be considered when planning long-term or baseline investigations of microbenthos to assure that the study adequately represents different habitats and that subsequent ecological inferences are valid.
\end{abstract}

KEY WORDS: Australia $\cdot$ Intertidal habitats $\cdot$ Microgastropods $\cdot$ Spatial scale $\cdot$ Patchiness

\section{INTRODUCTION}

Variation in distribution and abundance is a central theme of ecology and basic to both descriptive and experimental approaches to environmental science. There are, however, no simple patterns of variation, which has many implications for the development of ecological generalizations and predictive models of patterns of abundance and the processes influencing such patterns. Variation occurs at a hierarchy of different scales, from dispersion within and across patches of habitat (e.g. Morrisey et al. 1992a, Thompson et al. 1996, Underwood 1996a, Underwood \& Chapman 1996), to variation across habitats (e.g. Archambault \&

*E-mail: colabarr@bio.usyd.edu.au
Bourget 1996, Miller \& Ambrose 2000) up to distributions at a biogeographical scale (e.g. Kaustuv et al. 1998). Similarly, on a temporal scale, changes in abundances and distributions can change quite markedly over periods of days, months, decades, etc. (Menge et al. 1985, Barry \& Dayton 1991, Morrisey et al. 1992b).

The relations between temporal and spatial variation in abiotic variables and biological patterns and processes in aquatic assemblages are poorly understood, particularly the importance of small-scale variations in such measures. Patterns of reproduction, recruitment, dispersal, predation etc., often independent by time and space (Dayton \& Tegner 1984, Chapman \& Underwood 1998, Underwood 1999), and unpredictable indirect effects of interactions, can strongly influence any patterns observed (Menge et al. 1994, Menge 1995). Many marine environments are considered physically

(C) Inter-Research 2001 
unstable, although the persistence (Dayton \& Tegner 1984) of the biological components of these systems is unclear. Underwood \& Denley (1984) emphasized that predictability of community structure cannot depend exclusively on 'typical' areas but must include consideration of natural variability of the biota and their environment.

Numerous intrinsic ecological issues require detailed quantitative understanding of the scales at which there are predictable patterns in the abundances of animals and plants and the natural scales of variability in these patterns. Understanding the processes that regulate structure and dynamics of interactions among species requires recognition of the scales at which they operate and, therefore, quantitative description of spatial and temporal variation in abundances and diversity (Livingston 1987, Bourget et al. 1994, Metaxas \& Scheibling 1994, Underwood 1996a, Underwood \& Chapman 1998a). In addition, identification of scale- and habitat-dependent ecological patterns is central to management of fragmented habitats (Eggleston et al. 1999), and the statistical interaction between temporal and spatial variability is the focus of attention for detecting the magnitude of environmental perturbations (Underwood 1996b). Therefore, accurate description of patterns is a prerequisite to the understanding of ecological processes, development of general predictive models, assessment of environmental impacts, restoration of habitat and many practical managerial issues.

Although there is a long history of study of patterns of distribution and abundance, it has, until recently, been primarily focussed on responses of organisms to large-scale physical variables (e.g. patterns of zonation in response to emersion or alongshore changes in response to wave exposure; Lewis 1964). Recent emphasis on the importance of patchiness in ecological interactions (Pickett \& White 1985) has focussed on the large amounts of variability within and among patches of habitat, often at small spatial scales (e.g. Downing 1991, Lohse 1993, Chapman 1994, Chapman et al. 1995, Farnsworth \& Ellison 1996, Thompson et al. 1996, Underwood 1996a, Underwood \& Chapman 1996, 1998a). Such patterns have mostly been described for the larger components of fauna on intertidal rocky shores or of benthos in soft-sediments (e.g. Harris 1972, Coull et al. 1979, Phillips \& Fleeger 1985, Thrush 1986, 1991, Morrisey et al. 1992a,b, Hewitt et al. 1997, Schneider et al. 1997). These studies indicate that such patterns are variable and complex. Despite some studies carried out by Underwood (1996a) and Underwood \& Chapman (1996), there are few comparisons of the same suite of species across different habitats to test models of the importance of speciesspecific or habitat-specific characteristics in determin- ing patterns of and variability in abundance or distribution.

Diverse assemblages of small marine organisms occur in many natural habitats, e.g. mussel beds (Lohse 1993), algal beds (Akioka et al. 1999), kelp holdfasts (Moore 1973) or sediment (Morrisey et al. 1992a,b). These assemblages often contain many species that use similar resources (e.g. grazers on diatoms) but also different trophic levels (e.g. grazers, predators, detritivores). Such assemblages have great potential for measuring changes to biodiversity (Gee \& Warwick 1996) and assessing environmental impacts (Smith \& Simpson 1993). A diverse component of the assemblage can be found in small patches of habitat under a variety of different environmental conditions, they can develop in natural and artificial habitats placed in different areas (Costello \& Thrush 1991), and they can potentially be transplanted from site to site.

One component of intertidal fauna that forms an ideal test assemblage for many models of ecological processes and responses to environmental change are microgastropods (i.e. gastropods with adult size of $<2 \mathrm{~mm}$ ) because: (1) they are relatively quick and easy to identify without killing them; $(2)$ they can be handled, marked (for measures of growth, etc.) and moved among patches of habitat with little mortality; (3) they are very diverse and abundant in small patches of habitat; and (4) they have a wide range of phylogenetic and trophic levels. Despite their diverse nature, little is known about the basic ecology of most Australian microgastropods (Beesley et al. 1998) and there have been no quantitative descriptions of their spatial or temporal patterns of variability. However, studies on the basic ecology and life histories of European microgastropod species are most abundant, and some have shown the importance of substratum, mortality, recruitment and migration of adults in determining the pattern of spatio-temporal variation (Smith 1973, Wigham 1975, Southgate 1982, Fernández et al. 1988).

This paper describes patterns of variability of a subset of microgastropods at a hierarchy of spatial scales in 2 different habitats (sediment and coralline turf) on 1 shore. The study was done on a single shore because many larger intertidal gastropods on these shores show greatest variability in abundances at small spatial scales along single shores (Underwood \& Chapman 1996). It is also necessary to determine the scales of spatial replication needed to sample species representatively within a shore before valid comparisons can be made across shores. The spatial scales in this study varied from $<1$ to $300 \mathrm{~m}$. The species were chosen to represent different species in the same genus or family and a number of different families of primarily grazing snails. Coralline turf (i.e. algal beds composed primarily of erect coralline algae) are 
potentially very important habitats on intertidal rocky shores in temperate areas (Akioka et al. 1999). These habitats may modify the spatial distribution and abundance of associated fauna due to reduction of predation and protection from wave-exposure, and by offering different availability of trophic resources (Grahame \& Hanna 1989, Akioka et al. 1999). Intertidal and shallow subtidal sandy habitats are characterized by a high abundance and diversity of infaunal assemblages.

These data were used to test the hypotheses that: (1) as has been described for larger intertidal gastropods, most of the spatial variation in abundance of these microgastropods within each habitat is at small spatial scales, i.e. processes influencing small gastropods operate with a similar overall influence of small-scale processes; (2) closely related species show similar patterns of variation because of their similar responses to ecological processes; and (3) patterns of variation are similar across different habitats because similar processes occur in different habitats. This information is essential in characterizing variation in this assemblage and necessary for its use as 'indicators' of environmental change. In addition, this study is part of a larger study of natural temporal change in populations of individual species and the assemblage and relations of these patterns to aspects of life histories.

\section{MATERIALS AND METHODS}

Sampling design. The samples were collected on an intertidal shore in the Cape Banks Scientific Marine Research Area on the northern headland of Botany Bay, New South Wales, Australia (Fig. 1). Two different sheltered mid-shore habitats were chosen: coralline turf on intertidal rock platforms and patches of sandy sediment among intertidal boulders adjacent to the platforms. The turf was composed of tightly packed upright branches of coralline algae, primarily Corallina officinalis Linnaeus, forming a stiff matrix that held significant quantities of sand. Some patches of turf also included other taxa of articulated coralline algae (e.g. Jania spp., Amphiroa spp.).

The design incorporated 4 spatial scales in each of the 2 habitats. Two different locations were chosen to represent shores with orientations, slopes and wave exposures that are typical for the area (Fairweather \& Underwood 1991). Location 1 was oriented to the south-west with a slope of $10^{\circ}$ whereas location 2 was oriented to the west and a slope of $30^{\circ}$. Both locations were sandstone platforms and were separated by about $300 \mathrm{~m}$. In each location, 2 sites (patches within each of these locations) were randomly selected, $50 \mathrm{~m}$ apart. In each site, there were 2 randomly chosen replicate plots (smaller-scale patches that, in the case of the algal turf, were physically isolated from each other), $10 \mathrm{~m}$ apart. Finally, in each plot (approximately $2 \mathrm{~m}^{2}$ ), 3 replicate cores (potentially patches of habitat of different quality within each plot) were sampled. Each plot was sampled twice, 2 wk apart, in February 2000. Previous studies in soft-sediments (Nichols \& Thompson 1985, Livingston 1987, Morrisey et al. 1992b) and in mangroves (Underwood \& Chapman 1999) have shown large variability in the abundance and composition of fauna over periods of days, weeks or months. Therefore, the replicate cores were sampled to test the hypothesis that the patterns of abundance were consistent over short periods of time and to identify the scale of any spatio-temporal interactions.

Sampling methods. Samples were collected using a $10 \mathrm{~cm}$ diameter plastic corer. The corer was pushed

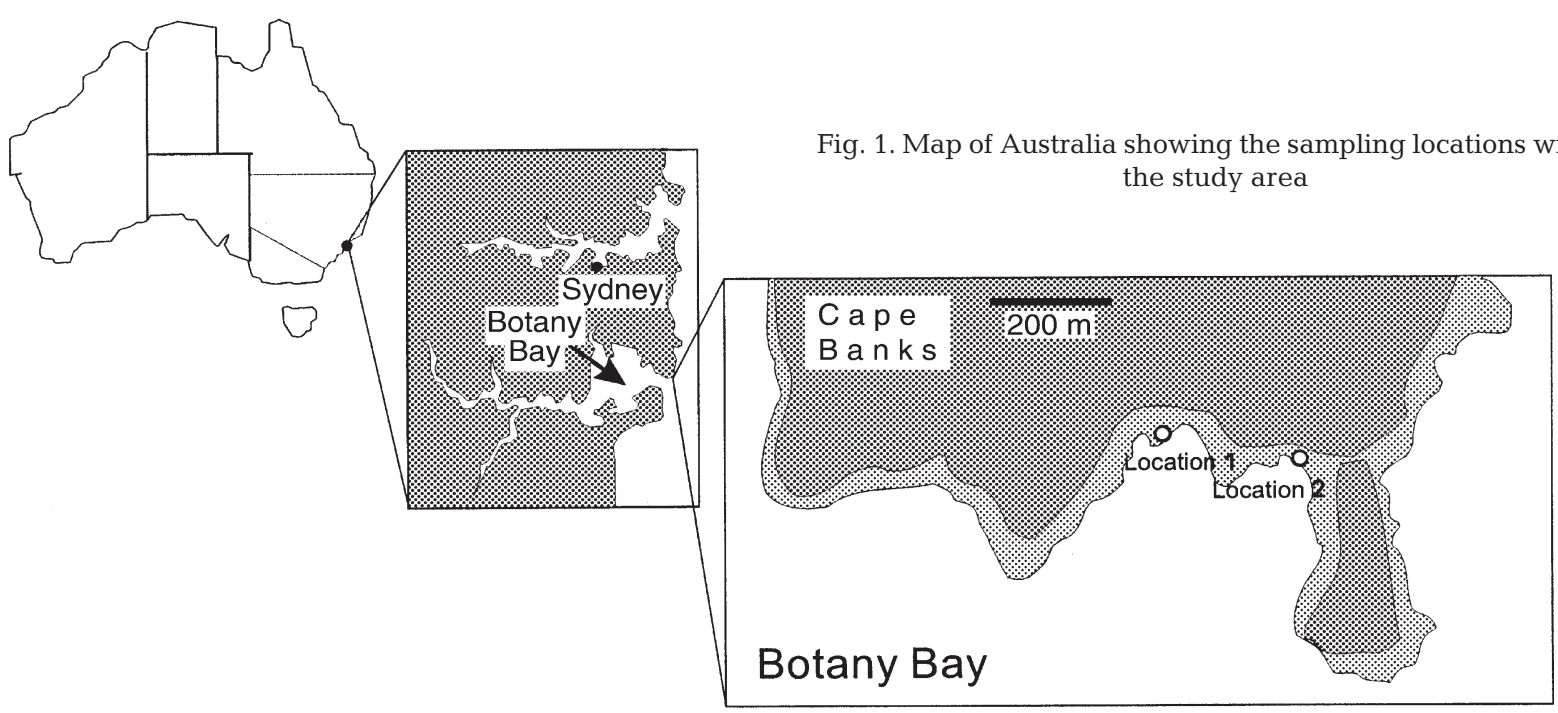


into the sediment to a depth of $5 \mathrm{~cm}$. In coralline turf, the corer was pushed into the turf and the algae and sediment inside the corer scraped off at the level of the rock. Because no direct statistical comparisons were made between habitats, it was not necessary to sample exactly the same volume of each habitat. Nevertheless, the turf was approximately $5 \mathrm{~cm}$ thick. A $10 \mathrm{~cm}$ corer was used because previous studies of the fauna in coralline turf in this area showed that the precision of the estimates of abundance obtained with this size of core was acceptable $(\mathrm{SE} / \overline{\bar{X}}<0.06$; B. Kelaher pers. comm.).

A pilot experiment was done on the fauna in coralline turf in order to evaluate the optimal number of replicates needed to provide a good estimate of spatial and temporal variability, while minimizing the amount of time taken to sort the samples. Twelve cores were taken from each of 2 plots (10 m apart) in each of 2 sites (50 m apart) in 1 location. The 5 most abundant species were sorted and the abundances analyzed by ANOVA. The purpose was to determine the minimal size of sample that could reliably measure abundance at a specific time. If estimates at a single time were imprecise, differences from time to time in any analysis of temporal change would be confounded with equally large spatial variation. For each analysis, the factors were 'sites', 'plots' nested within sites and 'times', i.e. different subsets of replicates chosen randomly from the sample of 12 to represent different times of sampling (although all replicates were, in fact, collected at the same time). For each set of analyses, different numbers of replicates were used, i.e. $\mathrm{n}=2, \mathrm{n}=3, \mathrm{n}=4$ and $\mathrm{n}=6$, picked at random from the 12 available (each with 1000 randomizations for each species and each experimental design). The frequency of significant temporal variation in these analyses provided information about the probability of detecting real temporal variation without confusion from spatial variability of very patchily distributed animals using small sample sizes. These data also allowed comparison of the spatial patterns using different numbers of replicates.

Samples were fixed in $7 \%$ formalin in seawater and sieved through a $63 \mu \mathrm{m}$ mesh. Eleven species of microgastropods from a variety of families were selected for analysis because they occurred in the 2 habitats, were relatively abundant in at least 1 of these habitats during this study and represent different species within a range of families (Table 1). Despite their large abundances in some habitats, there is little information about their basic ecology (Beesley et al. 1998). Most are thought to feed on micro-algae, diatoms and detritus, as inferred from the structure of their radulae, although Omalogyra liliputia probably feeds on the cell contents of larger algae, such as Ulva spp. (Ponder \& Keyzer 1998).

Analyses of data. Abundances of each species in each habitat and for each time were separately analyzed using nested ANOVA (locations, sites[locations] and plots[sites]) to get 2 independent measures of: (1) the scales at which there was significant spatial variability, and (2) the components of variation at each spatial scale. In addition, the data were re-analyzed with time of sampling as a 4 th factor to measure the spatial scale(s) at which there was short-term (2 wk) temporal interaction in these populations. All factors, spatial and temporal, were random. Homogeneity of variances was examined using Cochran's test, and in no case was it necessary to transform the data.

\section{RESULTS}

\section{Pilot experiment}

For all the species analyzed, the frequencies of significant temporal variation were low $(<6.5 \%)$ and were very similar when using different numbers of replicates (i.e. $\mathrm{n}=2, \mathrm{n}=3, \mathrm{n}=4$ and $\mathrm{n}=6$ ). These results indicated that whatever samples we used we obtained a

Table 1. Taxonomic relations of the species of microgastropods selected for this study

\begin{tabular}{|c|c|c|}
\hline Superfamily & Family & Species \\
\hline \multirow[t]{4}{*}{ Cingulopsoidea } & Eatoniellidae & Eatoniella atropurpurea (Frauenfeld 1867) \\
\hline & & Crassitoniella flammea (Frauenfeld 1867) \\
\hline & Cingulopsidae & Eatonina rubrilabiata Ponder \& Yoo 1980 \\
\hline & & Pseudopisinna gregaria gregaria Laseron 1950 \\
\hline \multirow[t]{5}{*}{ Rissooidea } & Anabathridae & Amphithalamus incidata (Frauenfeld 1867) \\
\hline & & Scrobs luteofuscus (May 1919) \\
\hline & & Scrobs elongatus Powell 1927 \\
\hline & & Pisinna olivacea (Frauenfeld, 1867) \\
\hline & & Anabathron contabulatum (Frauenfeld 1867) \\
\hline Rissoelloidea & Rissoellidae & Rissoella confusa roberstoni Ponder \& Yoo 1977 \\
\hline Omalogyroidea & Omalogyridae & Omalogyra liliputia (Laseron 1954) \\
\hline
\end{tabular}


good estimate of spatial variability of these patchy snails, without the risk of confounding with temporal variation. Moreover, the mean squares obtained in these analyses showed a consistent spatial pattern of the species, independent of the number of replicates used. Taking this into account and trying to minimize the costs and sorting times, we considered a sample size of $n=3$ to be suitable for obtaining a good estimate of variability.

\section{Scales of spatial variation}

All except 1 species, Scrobs luteofuscus, showed significant variation in abundances at some spatial scale in at least 1 of the 4 experiments ( 2 experiments in each of 2 habitats). Nevertheless, scales of variation differed among species and habitats, and between the 2 times of sampling.

For example, abundances of 8 of the 11 species showed significant variation among plots in the coralline turf, but only for Crassitoniella flammea and Pseudopisinna gregaria gregaria was this scale significant on each of the 2 sampling periods, even though these were only 2 wk apart (Table 2). In addition, for each of these species, the relative differences in abundances among the plots varied from one time to the next, i.e. different plots did not consistently have larger or smaller densities than other plots (Fig. 2a,b). Similar variability in plot-to-plot differences were shown for the other species, irrespective of whether differences among plots were significant (e.g. Scrobs luteofuscus Fig. 2c, Eatonina rubrilabiata Fig. 2d). Therefore, as predicted, in coralline most species showed small-scale variability in abundances, but these patterns varied across plots and sites and times of sampling.

Only 3 species, Scrobs elongatus, Rissoella confusa robertsoni and Omalogyra liliputia, showed significant variation in abundance in coralline turf at the scale of

Table 2. Results of ANOVA for abundances of 11 species of microgastropods in each of 2 habitats measured on 2 occasions (T1 and T2), 2 wk apart. ${ }^{*} \mathrm{p}<0.05$; ns: $\mathrm{p}>0.05$; X: insufficient data for analyses. See Table 1 for species abbreviations

\begin{tabular}{|c|c|c|c|c|c|c|c|c|c|c|c|c|c|}
\hline \multirow[t]{2}{*}{ Family } & \multirow[t]{2}{*}{ Species } & \multicolumn{6}{|c|}{ Coralline turf } & \multicolumn{6}{|c|}{ Sediment } \\
\hline & & $\mathrm{T} 1$ & $\mathrm{~T} 2$ & $\mathrm{~T} 1$ & $\mathrm{~T} 2$ & $\mathrm{~T} 1$ & $\mathrm{~T} 2$ & $\mathrm{~T} 1$ & $\mathrm{~T} 2$ & $\mathrm{~T} 1$ & $\mathrm{~T} 2$ & $\mathrm{~T} 1$ & $\mathrm{~T} 2$ \\
\hline \multirow[t]{2}{*}{ Eatoniellidae } & E. atropurpurea & ns & ns & ns & ns & ns & $*$ & ns & ns & ns & ns & ns & ns \\
\hline & C. flammea & ns & ns & ns & ns & $*$ & $*$ & $\mathrm{X}$ & ns & $\mathrm{X}$ & ns & $\mathrm{X}$ & ns \\
\hline \multirow[t]{2}{*}{ Cingulopsidae } & E. rubrilabiata & ns & ns & ns & ns & ns & * & ns & ns & ns & ns & ns & ns \\
\hline & P. gregaria gregaria & ns & ns & ns & ns & $*$ & * & ns & ns & ns & ns & ns & ns \\
\hline \multirow[t]{5}{*}{ Anabathridae } & A. incidata & ns & ns & ns & ns & ns & * & ns & ns & $*$ & ns & ns & ns \\
\hline & S. luteofuscus & ns & ns & ns & ns & ns & ns & ns & ns & ns & ns & ns & ns \\
\hline & S. elongatus & ns & ns & ns & $*$ & $*$ & ns & ns & $*$ & ns & ns & ns & ns \\
\hline & P. olivacea & ns & ns & ns & ns & * & ns & ns & $\mathrm{X}$ & $*$ & $\mathrm{X}$ & ns & $\mathrm{X}$ \\
\hline & A. contabulatum & ns & ns & ns & ns & ns & $*$ & $*$ & $*$ & ns & ns & ns & ns \\
\hline Rissoellidae & R. confusa robertsoni & $*$ & ns & ns & $*$ & ns & ns & ns & ns & ns & ns & ns & ns \\
\hline Omalogyridae & O. liliputia & ns & $*$ & ns & ns & ns & ns & ns & ns & ns & ns & ns & ns \\
\hline
\end{tabular}



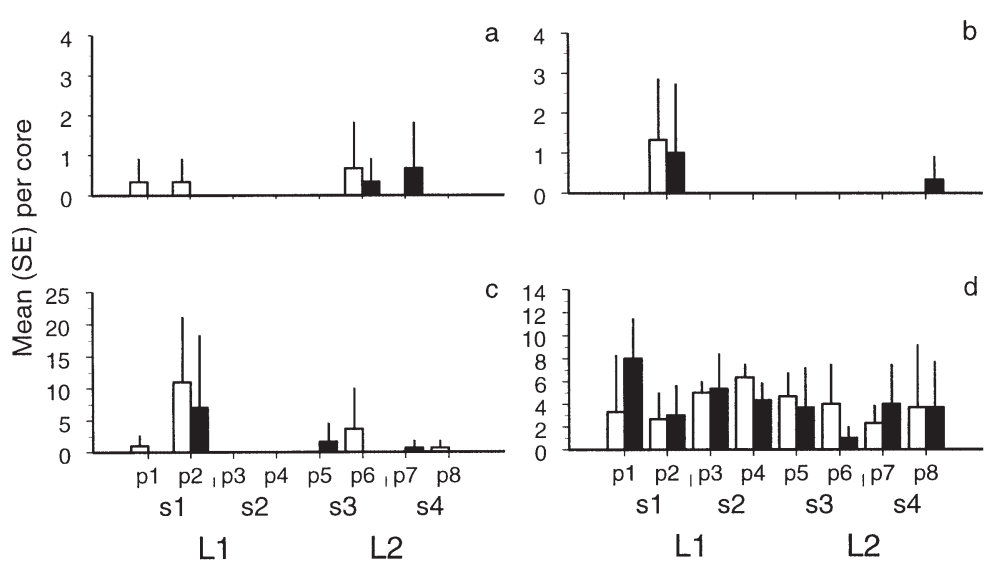

Fig. 3. Mean \pm SE numbers of individuals per core $(n=3)$ at each of the 2 times of sampling (empty and filled bars) for each plot in each location in the sandy sediment. (a) Anabathron contabulatum, (b) P. gregaria gregaria, (c) E. rubrilabiata,

(d) Amphithalamus incidata. See Fig. 2 for species and other abbreviations one time of sampling to the next (Fig. 3a). No species showed significant differences between plots in the sandy substratum, although many of the species were found in only 1 or a few plots (illustrated for Pseudopisinna gregaria gregaria and Eatonina rubrilabiata in Fig. 3b and Fig. 3c, respectively). The only species that was consistently found across plots in the sandy substratum was Amphithalamus incidata (Fig. 3d).

The components of variation for each of the 4 spatial scales investigated (i.e. $<1 \mathrm{~m}$ between cores [= residual], $10 \mathrm{~m}$ [between plots], $50 \mathrm{~m}$ [between sites] and $300 \mathrm{~m}$ [between locations]) were independently calculated from the mean square estimates for each habitat, each species and each time of sampling. There

sites and locations and, again, these patterns differed between the 2 sampling periods. These differences were generally due to large abundances at only 1 site in one of the locations (illustrated for $S$. elongatus in Fig. 2e). In no single experiment was there significant variation at more than 1 scale for any species.

There was very little variation in abundance of snails at any scale in the sediment. Four species showed significant differences in abundances at the scale of sites or locations, but only Anabathron contabulatum showed similar patterns of significance over the 2 experiments. Nevertheless, for this species, the differences in abundances differed between locations from

Table 3. Variance estimates (\%) derived from ANOVA for selected taxa from the 2 types of habitats (calculated according to Underwood 1997; -: negative estimates). Only variance estimates at small scale of cores (the residual) and plots from algal turf, and cores from sediment are shown. L: Location; S: Site. See Table 1 for species abbreviations

\begin{tabular}{|c|c|c|c|c|c|c|}
\hline & \multicolumn{4}{|c|}{ Coralline turf } & \multicolumn{2}{|c|}{ Sediment } \\
\hline & \multicolumn{2}{|c|}{ Time 1} & \multicolumn{2}{|c|}{ Time 2} & \multirow{2}{*}{$\begin{array}{c}\text { Time } 1 \\
\text { Residual }\end{array}$} & \multirow{2}{*}{$\begin{array}{c}\text { Time } 2 \\
\text { Residual }\end{array}$} \\
\hline & $\begin{array}{c}\text { Plot } \\
(\mathrm{L} \times \mathrm{S})\end{array}$ & Residual & $\begin{array}{c}\text { Plot } \\
(\mathrm{L} \times \mathrm{S})\end{array}$ & Residual & & \\
\hline E. atropurpurea & 24.91 & 51.69 & 40.69 & 20.76 & 66.66 & 97.64 \\
\hline A. incidata & 29.21 & 54.29 & 32.25 & 51.24 & 83.33 & 73.49 \\
\hline E. rubrilabiata & 37.88 & 45.84 & 18.91 & 27.92 & 64.28 & 94.44 \\
\hline S. luteofuscus & 8.04 & 91.96 & 0 & 94.44 & 79.38 & 82.21 \\
\hline S. elongatus & 26.06 & 27.67 & - & 59.09 & 88.13 & 76.74 \\
\hline P. gregaria gregaria & 35.89 & 57.02 & 65.26 & 19.14 & 70.73 & 100 \\
\hline P. olivacea & 40 & 60 & 33.33 & 66.66 & 42.10 & No test \\
\hline R. confusa roberstoni & i 15.38 & 61.53 & - & 36.73 & 100 & 100 \\
\hline O. liliputia & 4.61 & 84.61 & 22.35 & 63.41 & 76.54 & 63.62 \\
\hline C. flammea & 60 & 20 & 37.03 & 59.25 & No test & 90.1 \\
\hline A. contabulatum & 33.30 & 58.33 & 53.60 & 22.68 & 99.92 & 90.1 \\
\hline
\end{tabular}

was very large variability in these estimates between the 2 times of sampling, and many of the estimates at the scales of sites or locations were negative, indicating that the spatial variability at these scales was underestimated relative to that at the scale of plots (Underwood 1997). These components of variation were therefore not formally compared among species or habitats.

Nevertheless, for all species, very large proportions of the total variance were found at the scale of cores within plots (the Residual Mean Squares). These averaged $( \pm \mathrm{SE}) 52 \pm 5$ and $82 \pm 4 \%$ for the algal habitat and sediment, respectively (averaged across all species and the 2 times of sampling). Therefore, most of the variation in abundances was at the smallest spatial scale measured (Table 3). In the coralline algal turf, another $29 \pm 4 \%$ of the total variation was found at the scale of plots (ignoring 2 estimates out of 22 that were negative and, therefore, slightly overestimating this estimate). Similar calculations were not done for the sediment because of the larger number of negative estimates. For all species in each habitat, therefore, most variation was at the smallest spatial scales, particularly for the sediment (Table 3).

Because most of the variation in abundances was at the smallest spatial scale measured, the tests of the hypotheses that densities of the different species are spatially correlated used the number of individuals per core 
(tested for correlation using Pearson's r). Because many species were very patchy and present in only a few cores at any one time, these tests were restricted to those species that were relatively widespread, i.e. found in $75 \%$ or more of the cores in any habitat at either time of sampling. These species were Amphithalamus incidata, Eatoniella atropurpurea, Pseudopisinna gregaria gregaria, Omalogyra liliputia and Eatonina rubrilabiata.

Only 3 of the correlations were significant; numbers of Amphithalamus incidata and Eatoniella atropurpurea were positively correlated at each time of sampling $(\mathrm{r}=0.49, \mathrm{p}<0.05$ and $\mathrm{r}=0.70, \mathrm{p}<0.01$, respectively; Fig. 4a) and A. incidata and Pseudopisinna gregaria gregaria were positively correlated during the second sampling period ( $\mathrm{r}=0.80, \mathrm{p}<0.001$; Fig. 4b). For most species, despite very patchy distributions at very small spatial scales, densities were not correlated among species or abundances were too patchy for analysis, especially in the sediment.

Despite this small-scale patchiness (Figs 2 \& 3), there were substantial differences among species in their distributions and abundances in the 2 different habitats (Table 4). All species except Scrobs luteofuscus were more abundant in coralline turf than in sediment, although the magnitude of these differences varied markedly. These patterns showed no relation to the taxonomic relations of the different species. For example, the increase in abundance between the algal and sediment habitat for the 2 species in the Eatoniellidae varied between $700 \times$ for Eatoniella atropurpurea and $15 \times$ for Crassitoniella flammea (Table 4). Similarly, the 2 species of Scrobs showed different patterns, with $S$. luteofuscus more abundant in sediment and $S$. elongatus more abundant in coralline turf. In general, E. atropurpurea, Amphithalamus incidata and Pseudopisinna gregaria gregaria were the dominant species in coralline turf, while $A$. incidata and $S$. luteofuscus were the only 2 relatively abundant and widespread species in sediment.

Although temporal variability at different temporal scales is the focus of a related study, the consistency of these spatial scales of variation over a $2 \mathrm{wk}$ period was examined using ANOVA for each species and each habitat separately. There were significant interactions among patterns in time and space in 6 species (Eatoniella atropurpurea, Crassitoniella flammea, Pseudopisinna gregaria gregaria, Pisinna olivacea, Anabathron contabulatum and Rissoella confusa robertsoni). All showed significant interactions in abundances in the coralline turf, except for $P$. olivacea, which showed similar interactions in sediment, so patterns of spatial variability in this latter habitat were more consistent through time. Moreover, most interactions were at the 'plot' scale (E. atropurpurea,
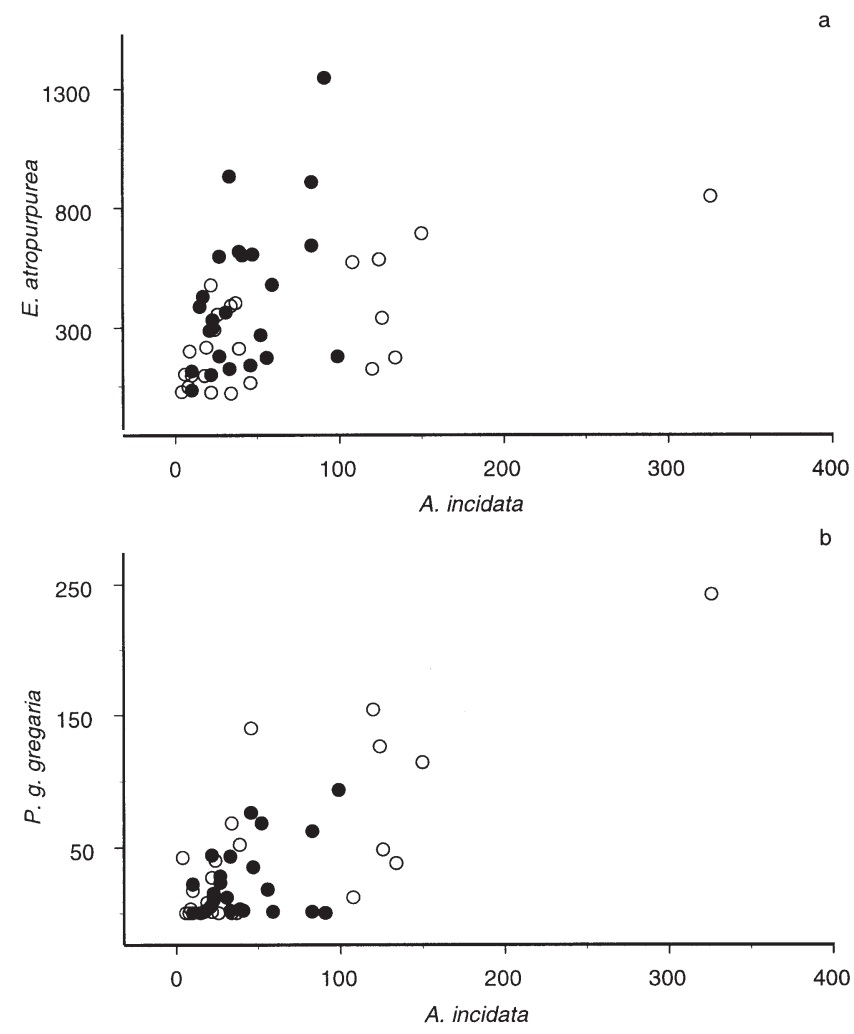

Fig. 4. Significant correlations between (a) the numbers of $A$. incidata and $E$. atropurpurea and (b) A. incidata and P. gregaria gregaria per core in coralline turf at the 2 times of sampling (time 1: empty symbols, time 2 filled symbols. See Fig. 2 for species abbreviations

$F_{4,32}=3.71, \mathrm{p}<0.05 ;$ C. flammea, $F_{4,32}=5.37, \mathrm{p}<$ $0.01 ;$ P. g. gregaria, $F_{4,32}=9.77, \mathrm{p}<0.001 ;$ A. contabulatum, $\left.F_{4,32}=2.70, \mathrm{p}<0.05\right)$, except for $P$. olivacea $\left(F_{2,36}=9.01, \mathrm{p}<0.001\right)$ and $R$. confusa robertsoni $\left(F_{2,36}=6.93, \mathrm{p}<0.01\right)$, which varied temporally at the 'site' scale.

Table 4. Mean \pm SE number of individuals per core for each species, averaged over the 2 times of sampling and all spatial scales $(\mathrm{n}=48)$. See Table 1 for species abbreviations

\begin{tabular}{|lcc|}
\hline Species & Coralline turf & Sediment \\
\hline E. atropurpurea & $349.7 \pm 40.9$ & $0.5 \pm 0.2$ \\
C. flammea & $1.5 \pm 0.6$ & $0.1 \pm 0.1$ \\
E. rubrilabiata & $16.4 \pm 2.5$ & $1.1 \pm 0.6$ \\
P. gregaria gregaria & $35.6 \pm 7.2$ & $0.2 \pm 0.1$ \\
A. incidata & $51.2 \pm 8.0$ & $4.1 \pm 0.4$ \\
S. luteofuscus & $1.3 \pm 0.4$ & $6.8 \pm 4.2$ \\
S. elongatus & $1.3 \pm 0.5$ & $0.0 \pm 0.0$ \\
P. olivacea & $2.0 \pm 0.4$ & $0.0 \pm 0.0$ \\
A. contabulatum & $2.7 \pm 1.0$ & $0.1 \pm 0.1$ \\
R. confusa roberstoni & $2.8 \pm 0.7$ & $0.1 \pm 0.0$ \\
O. liliputia & $12.4 \pm 1.7$ & $0.6 \pm 0.2$ \\
\hline
\end{tabular}




\section{DISCUSSION}

This mensurative study showed that abundances of microgastropods in coralline turf and sandy habitats are patchy at a number of different spatial scales, and this varied according to habitat. In each habitat, most variation was, as predicted, at the smallest spatial scale, i.e. among small cores of each habitat, spaced approximately $1 \mathrm{~m}$ apart. This was particularly the case in the sediment where more than $80 \%$ of the variation was found among replicate cores within $2 \mathrm{~m}^{2}$ sites. This small-scale variability is similar to patterns shown for other intertidal gastropods (e.g. Underwood \& Chapman 1996) and benthic macrofauna (e.g. Morrisey et al. 1992a) and re-emphasizes the need to accurately quantify patterns of abundance at a hierarchy of scales for understanding ecological processes (Bourget et al. 1994), measuring patterns of biodiversity (Underwood \& Chapman 1998a) and assessing environmental impacts (Underwood 1996a,b).

With respect to the consistency of patterns of variation across species and habitats, there were relatively consistent patterns between the 2 types of habitat. Ten of 11 species were more abundant in coralline turf than in sediment. For most species, despite the large amounts of small-scale variability among cores in each plot, there were also significant differences in abundances between plots (10 m apart) in turf in at least one of the sites during one or both experiments. In sediment, significant spatial variation was less common, but when found, was generally at the larger spatial scales of sites and locations. Nevertheless, examination of the mean abundances indicated that most species in sediment were common in only one or a few sites; no species was consistently found in greater numbers in all sites in one location compared to another location.

In addition, patterns of variability varied from one period of sampling to another, 2 wk later, in the coralline algal habitat where the animals were abundant, but not in the sediment. Again, this was generally manifested at the smallest spatial scale, i.e. densities varied from time to time at the scale of plots. With more detailed sampling designs, such small scales of spatiotemporal interaction are becoming more apparent as an essential feature of natural ecological variation (e.g. Morrisey et al. 1992b, Thrush et al. 1994, Underwood \& Chapman 1998b).

The spatial patterns of abundance therefore varied among species, habitats and times of sampling, and there was no close correlation between spatial patterns of abundance and taxonomic relations of the different species. The species responded to the spatial arrangement of habitats in a landscape according to the patchiness of habitat at a number of spatial scales, the type of habitat, environmental conditions (times of sam- pling) and characteristics of the species (e.g. McNeill \& Fairweather 1993, Egglestone et al. 1999).

At the scale of habitat, although all species were found in each habitat, only 1 of the 11 was more common in the sediment than in the coralline turf. Coralline turfs are structurally complex matrices, offering invertebrate animals refuges from predation (Akioka et al. 1999) and potentially a greater diversity and quantity of food (Edgar 1990, Bell et al. 1993). Coralline turf can result in greater rates of survival than in unvegetated habitats for many small organisms (Heck \& Crowder 1991). Whether the differences in abundance between the 2 types of habitat identified in this study are due to differences in mortality, recruitment or emigration and immigration is not, at this stage, known.

Numerous factors influence spatial heterogeneity in the distribution of organisms within habitats. Commonly, large-scale abiotic factors are considered important in defining broad patterns of distribution (Lewis 1964, Barry \& Dayton 1991). The large differences in and changes to abundances of microgastropods among patches of the same type of habitat a few meters apart may also be influenced by recruitment or mortality. Therefore, variation in the quality of habitat and limited dispersal may also partly explain their patchy patterns of abundance, although the patterns are likely to be modified by the adult animals redistributing themselves among patches of habitat (Underwood \& Chapman 1996). Although there are few data on rates of movement of adult microgastropods among patches of habitat, the adults appear to be active dispersers. New intertidal boulders are colonized by adult microgastropods within a few days of deployment (M. G. Chapman unpubl. data) and hundreds of small gastropods appear in new patches of algal turf within a couple of weeks (B. Kelaher pers. comm.). Many gastropods respond to small-scale features of their habitats and aggregate in response to cues from the habitat and each other. As a result, a change or difference in density in any area can potentially result in quite different responses and patterns of variance (Underwood \& Chapman 1992, Underwood 1996a). Short-term, dynamic patterns of immigration and emigration among patches of habitat are an important aspect of the ecology of small benthic animals, with strong local influences on patterns of abundance and distribution (e.g. Barnes 1998). Moreover, variations in recruitment rates can be a major cause of spatio-temporal variability among different habitats (e.g. Littorina acutispira; Underwood \& McFadyen 1983).

The heterogeneity of coralline turf is likely to affect the patchy distribution and abundance of microgastropods that associate with fronds or live among the trapped sediment. Most of the microgastropods in this 
study appeared to be associated with the sediment among Corallina, except for Eatoniella atropurpurea and Omalogyra liliputia. In the study area, the coralline turfs showed a great variability in compactness, which may influence detrital accumulation, thereby affecting sediment-dwelling populations. Small-scale changes in physical characteristics associated with such algae, such as accumulation of detritus and changes in water flow, have also been reported to directly or indirectly alter faunal abundance (Eckman 1987, Edgar et al. 1994).

Patchiness in the distribution of invertebrates in sediments has also been reported at small scales (e.g. Volckaert 1987, Morrisey et al. 1992a,b). Processes influencing distributions of organisms may change with scale (Thrush et al. 1994, 1997). For example, Hewitt et al. (1997) identified variable relations between adult and juvenile bivalves with changes in spatial scales in sediment. Although this variability is sometimes attributable to small-scale environmental or biological variables (e.g. Bell et al. 1978, Bell \& Coen 1982, Thrush 1986), much is still inexplicable with no clear environmental correlate(s). Similarly, patchiness and short-term variation in abundance and distribution of organisms have been shown in mangroves (Underwood \& Chapman 1999) and intertidal rocky shores (Underwood \& Chapman 1996, 1998b), although the latter have been focussed on large components of macrofauna. Nevertheless, studies on the spatio-temporal variability of faunal assemblages in algal turf have rarely been investigated or have been poorly done. As 2 examples of many, Hull (1997) examined seasonal changes of ostracods in only 1 patch of habitat, ignoring any potential variability at other spatial scales. In addition, Davenport et al. (1999) compared epifauna associated with 4 species of algae with each collected in a different patch $(<5 \mathrm{~m}$ apart), thus confounding species-specific and smallscale spatial variability.

This well-replicated mensurative experiment comparing a number of different species showed 2 striking features: first, the difference in the scales of spatial variance for 1 species from habitat to habitat; and second, the different spatial patterns of variation among closely related species, which (according to the limited literature available) were expected to have similar requirements for resources. Although all species examined occur in sediment and algal turfs, these obviously provide a different quality of habitat for the different species, but this is reflected in different patterns of variability. Spatial variation of invertebrates at different scales among habitats may be due to a real difference in the ecological processes operating from habitat to habitat, or simply spatial variation due to stochastic variability from one site to another
(Underwood 1996a). Furthermore, the lack of correlation between patterns of variability and taxonomic relations of the different species indicate that each species responded differently to ecological processes. These results underline the need to incorporate comparisons across habitats and species-level discrimination in any study about spatio-temporal variability at small scale.

Therefore, the present study has important consequences for studies of the distribution of microgastropods in different intertidal habitats, including those concerned with environmental monitoring. Coherent predictions about potential changes to populations in response to disturbances require understanding of interactive variances. An impact is definable in terms of change in the variance component that is associated with differences between abundances of populations in disturbed and control sites before and after the disturbance (Underwood 1996b). As a first step to measuring impact it is necessary to have quantitative data on natural patterns of spatial and temporal variation. Furthermore, to understand how and to predict under what circumstances impacts occur, it is necessary to know how and why the populations vary from place to place or time to time.

As mentioned above, many ecological and environmental studies are unreplicated or confounded because of inadequate attention to spatial and temporal scales of variance. When the scales at which variation occurs are not known in advance, sampling using nested designs can identify the relevant scales of variability to be incorporated into further research (Caffey 1985, Phillips \& Fleeger 1985, Jones et al. 1990, Morrisey et al. 1992a,b, Underwood 1997, Underwood \& Chapman 1998b). The scales can be chosen arbitrarily and adapted to the objectives of the particular study, although it is often useful to do a pilot study to identify scales at which variation is significant (Underwood 1997). The importance of the small spatial scales in patterns of abundance re-emphasizes the need to incorporate hierarchical scales of variability within locations for any comparisons among locations, be they to increase understanding of ecological patterns and processes, or to identify changes in assemblages in response to human disturbances.

Acknowledgements. This work was supported by funds from the Australian Research Council, the Institute of Marine Ecology and the Centre for Research on Ecological Impacts of Coastal Cities. We are grateful to many people for help with sampling, but particularly Stefanie Arndt, who worked hard in the field and laboratory. We thank Vanessa Mathews and Michelle Button for help with the graphics, and L. BenedettiCecchi and A. J. Underwood for commenting on an earlier draft of this paper. We also thank 3 anonymous referees for comments that improved the manuscript. 


\section{LITERATURE CITED}

Akioka H, Baba M, Masaki T, Johansen HW (1999) Rocky shore turfs dominated by Corallina (Corallinales, Rhodophyta) in northern Japan. Phycol Res 47:199-206

Archambault P, Bourget E (1996) Scales of coastal heterogeneity and benthic intertidal species richness, diversity and abundance. Mar Ecol Prog Ser 136:111-121

Barnes RSK (1998) The effects of movement on population density estimates of mudflat epifauna. J Mar Biol Assoc UK 78:377-385

Barry JP, Dayton PK (1991) Physical heterogeneity and the organization of marine communities. In: Kolasa J, Pickett STA (eds) Ecological heterogeneity. Springer-Verlag, New York, p 270-320

Beesley PL, Ross GJB, Wells A (1998) Mollusca: the southern synthesis. Fauna of Australia, Vol 5. CSIRO, Melbourne, Part A xvi 563 p. Part B viii 565-1234

Bell SS, Coen LD (1982) Investigations on epibenthic meiofauna. II. Influence of microhabitat and macroalgae on abundance of small invertebrates on Diopatra cuprea (Bosc) tube-caps in Virginia. J Exp Mar Biol Ecol 61:175-188

Bell SS, Watzin MC, Coull BC (1978) Biogenic structure and its effect on the spatial heterogeneity of meiofauna in a salt marsh. J Exp Mar Biol Ecol 35:99-107

Bell SS, Lechowicz MJ, Appenzeller A, Chandler M, DeBlois E, Jackson L, Mackenzie B, Preziozi R, Schallenberg M, Tinker N (1993) The spatial structure of the physical environment. Oecologia 96:114-121

Bourget E, Deguise J, Daigle G (1994) Scales of substratum heterogeneity, structural complexity, and the early establishment of a marine epibenthic community. J Exp Mar Biol Ecol 181:31-51

Caffey HM (1985) Spatial and temporal variation in settlement and recruitment of intertidal barnacles. Ecol Monogr 55:313-332

Chapman MG (1994) Small-scale patterns of distribution and size-structure of the intertidal littorinid, Nodilittorina pyramidalis in New South Wales. Aust J Ecol 19:83-95

Chapman MG, Underwood AJ (1998) Inconsistency and variation in the development of intertidal algal assemblages. J Exp Mar Biol Ecol 224:265-289

Chapman MG, Underwood AJ, Skilleter GA (1995) Variability at different spatial scales between a subtidal assemblage exposed to the discharge of sewage and two control assemblages. J Exp Mar Biol Ecol 189:103-122

Costello MJ, Thrush SF (1991) Colonization of artificial substrata as a multispecies bioassay of marine environmental quality. In: Jeffrey DW, Madden B (eds) Bioindicators and environmental management. Academic Press, London, p 401-418

Coull BC, Bell SS, Savory AM, Dudley BW (1979) Zonation of meiobenthic copepods in southeastern United States salt marsh. Estuar Coast Shelf Sci 9:181-188

Davenport J, Butler A, Cheshire A (1999) Epifaunal composition and fractal dimensions of marine plants in relation to emersion. J Mar Biol Assoc UK 79:351-355

Dayton PK, Tegner MJ (1984) Catastrophic storms, El Niño, and patch stability in a southern California kelp community. Science 224:283-285

Downing JA (1991) Biological heterogeneity in aquatic ecosystems. In: Kolasa J, Pickett STA (eds) Ecological heterogeneity. Springer, Berlin, p 160-180

Eckman JE (1987) The role of hydrodynamics in recruitment, growth and survival of Argopecten irradians (L) and Anomia simplex (D'Orbigny) within eelgrass meadows. J Exp Mar Biol Ecol 106:165-191
Edgar GJ (1990) The influence of plant structure on the species richness, biomass and secondary production of macrofaunal assemblages associated with Western Australian seagrass beds. J Exp Mar Biol Ecol 137:215-240

Edgar GJ, Shaw C, Watson GF, Hammond LS (1994) Comparisons of species richness, size-structure and production of benthos in vegetated and unvegetated habitats in Western Port, Victoria. J Exp Mar Biol Ecol 176:201-226

Eggleston DB, Elis WE, Etherington LL, Dahlgren CP, Posey $\mathrm{MH}$ (1999) Organism responses to habitat fragmentation and diversity: habitat colonization by estuarine macrofauna. J Exp Mar Biol Ecol 236:107-132

Fairweather PG, Underwood, AJ (1991) Experimental removals of a rocky intertidal predator: variations within two habitats in the effects on prey. J Exp Mar Biol Ecol 154: $29-75$

Farnsworth EJ, Ellison AM (1996) Scale-dependent spatial and temporal variability in biogeography of mangrove root epibiont communities. Ecol Monogr 66:45-66

Fernández E, Anadón R, Fernández C (1988) Life histories and growth of the gastropods Bittium reticulatum and Barleeia unifasciata inhabiting the seaweed Gelidium latifolium. J Moll Stud 54:119-129

Gee JM, Warwick RM (1996) A study of global biodiversity patterns in the marine motile fauna of hard substrata. J Mar Biol Assoc UK 76:177-184

Grahame J, Hanna FS (1989) Factors affecting the distribution of the epiphytic fauna of Corallina officinalis (L.) on an exposed rocky shore. Ophelia 30:113-129

Harris RP (1972) Horizontal and vertical distribution of the intertidal harpacticoid copepods of a sandy beach. J Mar Biol Assoc UK 52:493-505

Heck KL Jr, Crowder LB (1991) Habitat structure and predator-prey interactions in vegetated aquatic systems. In: Bell SS, McCoy ED, Mushinsky HR (eds) Habitat structure: The physical arrangement of objects in space. Chapman and Hall, New York, p 47-68

Hewitt JE, Legendre P, McArdle BH, Thrush SF, Bellehumeur C, Lawrie SM (1997) Identifying relationships between adult and juvenile bivalves at different spatial scales. J Exp Mar Biol Ecol 216:77-98

Hull SL (1997). Seasonal changes in diversity and abundance of ostracods on four species of intertidal algae with differing structural complexity. Mar Ecol Prog Ser 161:71-82

Jones GP, Ferrell DJ, Sale PF (1990) Spatial pattern in the abundance and structure of mollusc populations in the soft sediments of a coral reef lagoon. Mar Ecol Prog Ser 62: 109-120

Kaustuv R, Jablonski D, Valentine JW, Rosenberg G (1998) Marine latitudinal diversity gradients: Tests of causal hypotheses. Proc Natl Acad Sci USA 95:3699-3702

Lewis JR (1964) The ecology of rocky shores. English University Press, London

Livingston RJ (1987) Field sampling in estuaries: the relationship of scale to variability. Estuaries 10:194-207

Lohse DP (1993) The importance of secondary substratum in a rocky intertidal community. J Exp Mar Biol Ecol 166:1-17

McNeill SE, Fairweather PG (1993) Single large or several small marine reserves? An experimental approach with seagrass fauna. J Biogeogr 20:429-440

Menge BA (1995) Indirect effects in marine rocky intertidal interaction webs: patterns and importance. Ecol Monogr 65:21-74

Menge BA, Lubchenco J, Ashkenas LR (1985) Diversity, heterogeneity and consumer pressure in a tropical rocky intertidal community. Oecologia 65:394-405

Menge BA, Berlow EL, Blanchette CA, Navarette SA, 
Yamada SB (1994) The keystone species concept: variation in interaction strength in a rocky intertidal habitat. Ecol Monogr 64:249-286

Metaxas A, Scheibling RE (1994) Spatial and temporal variability of tidepool hyperbenthos on a rocky shore in Nova Scotia, Canada. Mar Ecol Prog Ser 108:175-184

Miller AW, Ambrose RF (2000) Sampling patchy distributions: comparison of sampling designs in rocky intertidal habitats. Mar Ecol Prog Ser 118:1-14

Moore PG (1973) The larger Crustacea associated with holdfasts of kelp (Laminaria hyperborea) in north-east Britain. Cah Biol Mar 14:493-518

Morrisey DJ, Howitt L, Underwood AJ, Stark JS (1992a) Spatial variation in soft-sediment benthos. Mar Ecol Prog Ser 81:197-204

Morrisey DJ, Underwood AJ, Howitt L, Stark JS (1992b) Temporal variation in soft-sediment benthos. J Exp Mar Biol Ecol 164:233-245

Nichols FH, Thompson JK (1985) Persistence of an introduced mudflat community in South San Francisco Bay, California. Mar Ecol Prog Ser 24:83-97

Phillips FE, Fleeger JW (1985) Meiofauna meso-scale variability in two estuarine habitats. Estuar Coast Shelf Sci 21: 745-756

Pickett STA, White PS (1985) The ecology of natural disturbance and patch dynamics. Academic Press Inc., Orlando

Ponder WF, Keyzer RG (1998) Superfamily Omalogyroidea. In: Beesley PL, Ross GJB, Wells A (eds) Mollusca: the southern synthesis. Fauna of Australia, Vol 5. CSIRO Publishing, Melbourne, p 864-865

Schneider DC, Walters R, Thrush S, Dayton P (1997) Scale-up of ecological experiments: density variation in the mobile bivalve Macoma liliana. J Exp Mar Biol Ecol 216:129-152

Smith SDA (1973) The population biology of Lacuna pallidula (da Costa) and Lacuna vincta (Montagu) in north-east England. J Mar Biol Assoc UK 53:493-520

Smith SDA, Simpson RD (1993) Effects of pollution on holdfast macrofauna of the kelp Ecklonia radiata: discrimination at different taxonomic levels. Mar Ecol Prog Ser 96:199-208

Southgate T (1982) The biology of Barleeia unifasciata (Gastropoda: Prosobranchia) in red algal turfs in southwest Ireland. J Mar Biol Assoc UK 62:461-468

Thompson RC, Wilson BJ, Tobin ML, Hill AS, Hawkins SJ (1996) Biologically generated habitat provision and diversity of rocky shore organisms at a hierarchy of spatial scales. J Exp Mar Biol Ecol 202:73-84

Thrush SF (1986) Spatial heterogeneity in subtidal gravel generated by the pit-digging activities of Cancer pagurus. Mar Ecol Prog Ser 30:221-227

Thrush SF (1991) Spatial patterns in soft-bottom communities. TREE 6:75-79

Thrush SF, Pridmore RD, Hewitt JE (1994) Impacts on softsediment macrofauna: the effects of spatial variation on temporal trends. Ecol Appl 41:31-41

Turner SJ, Grant J, Pridmore RD, Hewitt JE, Wilkinson MR, Hume TM, Morrisey DJ (1997) Bedload and water-column

Editorial responsibility: Otto Kinne (Editor),

Oldendorf/Luhe, Germany transport and colonization processes by post-settlement benthic macrofauna: does infaunal density matter? J Exp Mar Biol Ecol 216:51-76

Underwood AJ (1996a) Spatial patterns of variance in density of intertidal populations. In: Floyd RB, Sheppard AW, De Barro PJ (eds) Frontiers of population ecology. CSIRO, Melbourne, p 369-389

Underwood AJ (1996b) On beyond BACI: sampling designs that might reliably detect environmental disturbances. In: Schmitt RJ, Osenberg CW (eds) Detecting ecological impacts: concepts and applications in coastal habitats. Academic Press, San Diego, p 151-175

Underwood AJ (1997) Experiments in ecology: their logical design and interpretation using analysis of variance. Cambridge University Press, Cambridge

Underwood AJ (1999) History and recruitment in structure of intertidal assemblages on rocky shores: an introduction to problems for interpretation of natural change. In: Whitfield M, Matthews J, Reynolds C (eds) Aquatic life cycle strategies: survival in a variable environment. Mar Biol Assoc UK, p 79-96

Underwood AJ, Chapman MG (1992) Experiments on topographic influences on density and dispersion of Littorina unifasciata in New South Wales. In: Grahame J, Mill PJ, Reid DG (eds) Proceedings of the third international symposium on littorinid biology. The Malacological Society of London, London, p 185-195

Underwood AJ, Chapman MG (1996) Scales of spatial patterns of distribution of intertidal invertebrates. Oecologia 107:212-224

Underwood AJ, Chapman MG (1998a) A method for analysing spatial scales of variation in composition of assemblages. Oecologia 117:570-578

Underwood AJ, Chapman MG (1998b) Spatial analyses of intertidal assemblages on sheltered rocky shores. Aust J Ecol 23:138-157

Underwood AJ, Chapman MG (1999) Problems and practical solutions for quantitative assessment of biodiversity of invertebrates in coastal habitats. In: Ponder W, Lunney D (eds) The other $99 \%$. The conservation and biodiversity of invertebrates. Royal Zoological Society of New South Wales, Mosman, p 19-25

Underwood AJ, Denley EJ (1984) Paradigms, explanations, and generalizations in models for the structure of intertidal communities on rocky shores. In: Strong DR, Simberloff D, Abele LG, Thistle AB (eds) Ecological communities: conceptual issues and the evidence. Princeton University Press, Princeton, p 151-180

Underwood AJ, McFadyen KE (1983) Ecology of the intertidal snail Littorina acutispira Smith. J Exp Mar Biol Ecol 66: 169-197

Volckaert F (1987) Spatial pattern of soft-bottom Polychaeta off Nova Scotia, Canada. Mar Biol 93:627-639

Wigham GD (1975) The biology and ecology of Rissoa parva (da Costa) (Gastropoda: Prosobranchia). J Mar Biol Assoc UK 55:45-67

Submitted: September 15, 2000; Accepted: February 27, 2001 Proofs received from author(s): September 4, 2001 